$1-1-2007$

\title{
Investigation of Dimensions of Social-Emotional Classroom Behavior and School Readiness for Low-Income Urban Preschool Children
}

John Fantuzzo

University of Pennsylvania, JOHNF@GSE.UPENN.EDU

Rebecca Bulotsky-Shearer

Erikson Institute

Paul McDermott

University of Pennsylvania

Christine McWayne

New York University

Douglas Frye

University of Pennsylvania

Follow this and additional works at: https://repository.upenn.edu/gse_pubs

- next page for additional authors

Part of the Blingual, Multillngual, and Multicultural Education Commons

\section{Recommended Citation}

Fantuzzo, J., Bulotsky-Shearer, R., McDermott, P., McWayne, C., Frye, D., \& Perlman, S. (2007). Investigation of Dimensions of Social-Emotional Classroom Behavior and School Readiness for Low-Income Urban Preschool Children. Retrieved from https://repository.upenn.edu/gse_pubs/124

Postprint version. Published in School Psychology Review, Volume 36, Issue 1, 2007, pages 44-62.

We have contacted the publisher regarding the deposit of this paper in ScholarlyCommons@Penn. No response has been received.

This paper is posted at ScholarlyCommons. https://repository.upenn.edu/gse_pubs/124

For more information, please contact repository@pobox.upenn.edu. 


\title{
Investigation of Dimensions of Social-Emotional Classroom Behavior and School Readiness for Low-Income Urban Preschool Children
}

\author{
Abstract \\ The present study identified higher-order relationships among teacher assessments of approaches to \\ learning and emotional and behavioral adjustment constructs for urban, low-income preschool children. It \\ examined the unique contribution of these dimensions to cognitive and social competencies and risk of \\ poor academic outcomes. Analyses of a large, representative sample of urban Head Start children \\ revealed two distinct and reliable, higher-order dimensions of classroom adjustment behavior: Regulated \\ and Academically Disengaged Behavior. Both of the dimensions contributed unique variance to the \\ prediction of early mathematics ability and general classroom competencies prior to kindergarten entry, \\ controlling for child demographics. Each dimension also contributed independently to the prediction of \\ academic risk, controlling for child demographics. Implications for practice and policy were discussed.

\section{Disciplines} \\ Bilingual, Multilingual, and Multicultural Education

\section{Comments} \\ Postprint version. Published in School Psychology Review, Volume 36, Issue 1, 2007, pages 44-62. \\ We have contacted the publisher regarding the deposit of this paper in ScholarlyCommons@Penn. No \\ response has been received.

\section{Author(s)} \\ John Fantuzzo, Rebecca Bulotsky-Shearer, Paul McDermott, Christine McWayne, Douglas Frye, and Staci \\ Perlman
}


Running head: DIMENSIONS OF SOCIAL-EMOTIONAL CLASSROOM BEHAVIOR

\author{
Investigation of Dimensions of Social-Emotional Classroom Behavior \\ and School Readiness for Low-Income Urban Preschool Children
}

John Fantuzzo

University of Pennsylvania

Rebecca Bulotsky-Shearer

Erikson Institute

Paul McDermott

University of Pennsylvania

Christine McWayne

New York University

Douglas Frye and Staci Perlman

University of Pennsylvania

[School Psychology Review(2007), 36, 44-62]

John Fantuzzo (johnf@gse.upenn.edu), Paul McDermott (drpaul4@verizon.net), Douglas Frye (dfrye@gse.upenn.edu), Staci Perlman (speckham@sp2.upenn.edu), University of Pennsylvania, Graduate School of Education, 3700 Walnut Street, 19104-6216.

Rebecca Bulotsky-Shearer (rshearer@erikson.edu), Erikson Institute, 420 North Wabash, Chicago, Illinois 60611-5627

Christine McWayne (cm106@nyu.edu), New York University, Department of Applied Psychology, 239 Greene Street, Suite 537, New York, NY 10003

Acknowledgment. This research project was supported in part by Head Start Research Partnership grants and a grant \#HD 046168, with funding from the Administration for Children and Families; the Assistant Secretary for Planning and Evaluation; the US Department of Education: Office of Special Education Programs, Institute for Education Sciences; and the National Institute of Child Health and Human Development. Special thanks go to our collaborators at Office of Early Childhood Education in the School District of Philadelphia. This includes Donna Piekarski and Jennifer Plumer Davis. Correspondence concerning this article should be addressed to the first author at The Penn Graduate School of Education, University of Pennsylvania, 3700 Walnut Street, Philadelphia, PA 19104-6216. 


\begin{abstract}
The present study identified higher-order relationships among teacher assessments of approaches to learning and emotional and behavioral adjustment constructs for urban, low-income preschool children. It examined the unique contribution of these dimensions to cognitive and social competencies and risk of poor academic outcomes. Analyses of a large, representative sample of urban Head Start children revealed two distinct and reliable, higher-order dimensions of classroom adjustment behavior: Regulated and Academically Disengaged Behavior. Both of the dimensions contributed unique variance to the prediction of early mathematics ability and general classroom competencies prior to kindergarten entry, controlling for child demographics. Each dimension also contributed independently to the prediction of academic risk, controlling for child demographics. Implications for practice and policy were discussed.
\end{abstract}


Investigation of Dimensions of Social-Emotional Classroom Behavior and School Readiness for Low-Income Urban Preschool Children

With the passing of No Child Left Behind, American public schools are being held accountable to ensure that all children are meeting minimum academic standards by third grade (U.S. Department of Education, 2004). Research has indicated that only 32\% of fourth graders in the US met literacy proficiency standards (Reyna, 2005). Furthermore, minority children disproportionately performed below minimum proficiency standards in both literacy and mathematics (Reyna). By establishing third grade as the point of accountability, the No Child Left Behind legislations affirms the significance of early childhood education and the necessity of effective early identification and intervention.

A large body of empirical literature emphasizes the importance of early childhood intervention. Three National Research Council reports, Eager to Learn (2001), From Neurons to Neighborhoods (2000), and Preventing Reading Difficulties in Young Children (1998), highlight the early childhood years as a critical time period for development. Research documents that the competencies young children acquire during these years form the foundation on which they will develop and build future competencies (National Research Council, 2000). Young children exposed to social and biological risk factors are at greater risk for not developing these foundational competencies, placing them at future risk of poor school performance (Sameroff \& Fiese, 2000). Furthermore, quality early care and education has been found to promote positive school outcomes, particularly for vulnerable young children living in poverty (Kolker, Osborne, \& Schnurer, 2004; Lynch, 2004).

Head Start is our nation's largest federally sponsored early childhood program developed to serve at-risk, vulnerable young children by promoting school readiness (Zigler, Finn- 
Stevenson, \& Hall, 2002). Informed by a comprehensive, developmental model Head Start targets eight key domains of development to enhance readiness; these include Language Development, Literacy, Mathematics, Science, Creative Arts, Physical Health, Approaches to Learning, and Social and Emotional Development [U.S. Department of Health and Human Services (USDHHS), 2003]. Historically, Head Start's primary goal was to enhance social competence. In recent years, this has shifted to emphasize cognitive, school readiness skills in conjunction with the No Child Left Behind legislation. This has placed a greater emphasis in Head Start on early reading competencies and other cognitive competency. Early mathematics has been identified as another set of key cognitive readiness competencies for low-income preschool children (Jordan, Huttonlocher, \& Levine, 1994; Jordan, Kaplan, Olah, \& Locuniak, 2006). This shift has generated concern by many early childhood advocates that the promotion of foundational approaches to learning and social emotional competencies will be deemphasized in early childhood curriculum and as a result children will be placed at greater risk for poor school adjustment (Raver \& Zigler, 2004). This fear is supported by national surveys of kindergarten teachers who report that their primary concern is that children - particularly those living in poverty - are not entering kindergarten with the basic learning behaviors and social-emotional competencies that they need to transition successfully into a formal learning environment (Rimm-Kaufman, Pianta, \& Cox, 2000).

These policy debates about the primary focus of early childhood intervention place a premium on early childhood research that examines the relationships between approaches to learning and social and emotional competencies and early academic success (Knitzer 2003; Raver \& Knitzer, 2002). Approaches to learning are recognized as distinct, observable behaviors that indicate ways children become engaged in classroom interactions and learning activities. In 
recent years, Head Start (USDHHS, 2003) and the National Educational Goals Panel (1997) have underscored the particular significance of learning behaviors; they are included as essential components of children's school readiness and have been identified as the least understood and the least researched school readiness competency (Kagan, Moore, \& Bredekamp, 1995). A programmatic line of research by McDermott and colleagues (McDermott, 1999; McDermott, Mordel, \& Stoltzfus, 2001; Stott, McDermott, Green \& Francis, 1988) has defined learning behaviors as observable behavior patterns that children display as they approach and undertake classroom learning tasks. Specific behaviors that reflect this construct include initiative, curiosity, cooperativeness, engagement, and persistence (USDHHS, 2003; McDermott, 1999).

Research suggests that learning behaviors such as persistence and attention, contribute to school readiness in other relevant domains (i.e., early mathematics and literacy outcomes) (Fantuzzo, Perry, \& McDermott, 2004; Green \& Francis, 1988; McDermott, 1984; McDermott, Leigh, \& Perry, 2002; McWayne, Fantuzzo, \& McDermott, 2004). A study conducted by McDermott (1984) with school-aged children found that the interaction of IQ and learning style predicted a significant amount of the variance in children's early math, reading, and language. Research with preschool children suggests that preschool approaches to learning, including competence motivation, attention/persistence, and attitude towards learning, also positively relate to early academic outcomes (McWayne et al., 2004). Further, a positive relationship has been found between preschool learning behaviors, such as competence motivation and persistence, and social skills, such as self-control (Fantuzzo et al., 2004; McDermott et al., 2002).

In addition, social and emotional adjustment has received much attention nationally as a foundational competency linked to early school adjustment. This construct reflects a composite set of skills including self-regulation, self-concept, self-efficacy, and prosocial behaviors with 
teachers and peers (National Education Goals Panel, 1997). A large body of research provides evidence that this constellation of skills strongly relates to school readiness and future school success (Huffman, Mehlinger, \& Kerivan, 2000; LaParo \& Pianta, 2000; McClelland, Morrison, \& Holmes, 2000; Teo, Carlson, Mathieu, Egeland, \& Sroufe, 1996). For example, self-regulation and prosocial behavior are associated with higher early numeracy and literacy skills upon school entry and beyond (McClelland et al., 2000; Teo et al., 1996). Conversely, early social and emotional difficulties are associated with lower performance with respect to these key learning outcomes (Fantuzzo, Bulotsky, McDermott, Mosca, \& Lutz, 2003; Lonigan, Bloomfield, Anthony, Bacon, Philips, \& Samwel, 1999; Velting \& Whitehurst, 1997).

This research provides evidence that for preschool children classroom approaches to learning and social and emotional adjustment are key contributors to early school success. While studies underscore their importance as foundational skills that promote children's connection to social and academic learning in the classroom, this research has a number of limitations. First, existing research examines the isolated contribution of each set of skills to school success (e.g., either approaches to learning or classroom social and emotional adjustment). Both of these constructs reflect rich, multidimensional aspects of children's classroom behavioral conduct; yet their potential overlap is not empirically examined. This is particularly important given the findings of a recent study examining the dimensionality of the Problem Behavior Scale and the Social Skills Scale of the teacher version of the Social Skills Rating System, with urban Head Start children (Fantuzzo, Manz, \& McDermott, 1998). Findings from this study indicated that instead of representing two independent constructs of social competence (behavior problems and social skills), the two multidimensional scales represented inverse poles of the one higher-order dimension; that is one pole was classroom social problems and the other pole was social 
competence (Fantuzzo et al., 1998). Particularly for this vulnerable population of children, research should explore the question: “Are approaches to learning and classroom social and emotional adjustment observed by teachers really distinct competencies (useful, meaningful, unique dimensions) or are they different poles of the same dimension?” Second, research should examine the unique relationships of these higher order dimensions to academic outcomes. This will extend our understanding of the contribution of these interrelated multidimensional constructs to key outcomes for low-income preschool children.

Finally, there is a need to understand the contribution of approaches to learning and classroom social and emotional adjustment to the identification of risk and special needs for vulnerable children. A recent report by the Surgeon General (USDHHS, 2001) highlights the importance of early identification and intervention for children with social and emotional needs. The report calls for the creation of reliable and valid methods for identifying early behavioral needs so that timely and appropriate interventions can be implemented before problems intensify or become more long-standing (USDHHS). These methods should reduce stigma and improve access to services, particularly for those children most at risk. One method that has been recognized as a valuable and cost-efficient way to identify social and emotional functioning across a large numbers of children is the use of behavior rating scales (Lidz, 2003).

Research is needed that uses reliable and valid teacher behavior rating scales for Head Start children to investigate higher order dimensions of classroom approaches to learning and social and emotional adjustment and to determine their unique contribution to cognitive competencies and the prediction of future risk. The purpose of the present study was to address three research questions: First, are there distinct and reliable higher order relationships among classroom approaches to learning and emotional and behavioral adjustment constructs for low- 
income preschool children? Second, are these behavioral dimensions uniquely associated with early mathematics ability and other classroom learning outcomes in Head Start? Third, do these dimensions differentially predict poor future academic performance?

Method

\section{Participants}

A sample of 1,764 children, enrolled in a large urban school district Head Start program in the northeast, served as participants to examine the latent structure across approaches to learning and problem behavior constructs. The children ranged in age from 44 to 81 months $(M=59, S D=6.6)$. Gender was evenly distributed (50\% were male). The majority were AfricanAmerican (81\%), with the remaining 8\% Hispanic, 7\% Caucasian, 3\% Asian, and 1\% other. Family income in the program matched national proportions for urban Head Start programs, with annual income for $94 \%$ of the families falling below $\$ 12,000$. An equal number of boys and girls were randomly selected from 150 participating classrooms. The classrooms were selected to be representative of the six geographic regions and the demographics of the entire cohort of 5,000 Head Start children. The demographic breakdown of the entire cohort was 50\% male, 78\% African-American, 9\% Hispanic, Caucasian, 8\%, and 5\% Asian and other. This cohort is demographically different from the national racial/ethnic distribution of Head Start children, with 31\% being African-American, 31\% being Hispanic, 27\% being Caucasian, and 11\% Asian and other (USDHHS, 2005). The overall participation rate was 95\%.

Two smaller samples of the same Head Start children were used to determine the unique contributions of behavioral dimensions to dimensions of school readiness and risk prior to kindergarten entry, respectively ( $n=232$ and $n=145)$. These children ranged in age from 50 to 69 months $(M=63, S D=3.9)$. Gender was evenly distributed (47\% female) with the majority 
African American (82\%). An equal number of boys and girls were selected from 50 participating classrooms which were representative of the six geographic regions. The overall participation rate was $90 \%$.

\section{Measures: Early Fall}

Emotional and behavioral adjustment problems. Preschool emotional and behavioral adjustment problems were measured by the Adjustment Scales for Preschool Intervention (ASPI; Lutz, Fantuzzo, \& McDermott, 2002), a multidimensional instrument based on teacher observations of adaptive and maladaptive behavior in the preschool classroom. The ASPI was standardized on a sample of urban Head Start children and validated for use with this population (for more extensive description of standardization, see Lutz et al., 2002). The ASPI contains 144 observable preschool classroom behaviors (122 items reflect problem behaviors, 22 items reflect positive behaviors). These items are each framed by 22 routine classroom situations such as, interactions with teacher, peers, and involvement in structured and unstructured classroom activities, games and play. ASPI content focuses on teacher observed behavior over the preceding 2 months.

Construct validity studies of ASPI with urban, low-income preschool populations have revealed five robust and reliable dimensions: Aggressive, Oppositional, Inattentive/Hyperactive, Withdrawn/Low Energy and Socially Reticent. Each of the five dimensions demonstrated adequate internal consistency, with Cronbach alpha coefficients of .92, .78, .79, .85 and .79 respectively (Lutz et al., 2002). Convergent and divergent validity of the five ASPI dimensions has been established with constructs of interactive peer play, behavior problems, temperament, emotion regulation, and direct observations of classroom behavior problems (Bulotsky-Shearer \& Fantuzzo, 2004). Predictive validity of the five ASPI dimensions has also been established 
with end-of-the-year preschool competencies including interactive peer play, classroom learning competencies, and receptive language skills (Fantuzzo et al., 2003)

Approaches toward learning. The Preschool Learning Behaviors Scale (PLBS;

McDermott, Green, Francis, \& Stott, 2000) is a 29-item teacher rating scale of observable learning behaviors within the classroom context (McDermott et al., 2002). Construct validity was established with two national samples, revealing three reliable dimensions: Competence Motivation, Attention/Persistence, and Attitudes toward Learning (Cronbach’s alpha coefficients of $.85, .83$, and .75 , respectively). Convergent and divergent validity was established for urban, low-income preschool children (Fantuzzo et al., 2004; McDermott et al., 2002). Measures: End of the Year

Early mathematics ability. The Test of Early Mathematics Ability - Second Edition (TEMA-2; Ginsberg \& Baroody, 1990) is a 65-item individually administered test of children’s early math abilities. The TEMA measures concepts of relative magnitude, reading and writing numerals, counting skills, number facts, calculation, calculation algorithms, and base-ten concepts for children ages 3.0 - 8.11 months. This test was normed on a nationally representative sample of 896 children across 27 states. Internal consistencies were high across all age ranges, as was test-retest reliability (Ginsberg \& Baroody). Criterion validity was established through correlations with the TEMA, Diagnostic Achievement Battery (DAB-3; Newcomer, 2001), and Quick Score Achievement Test (Q-SAT; Hammill, Ammer, Cronin, Mandlebaum, \& Quinby, 1987).

Classroom learning competence. The Child Observation Record (COR; High Scope Educational Research Association, 1992) is a 30-item observationally-based measure of preschool development that is based on teacher-report. The COR measures several domains 
including emergent literacy, numeracy, social and motor competencies of children ages $2 \frac{1}{2}$ to 6 years in early childhood settings (Schweinhart, McNair, Barnes, \& Larner, 1993). Exploratory factor analysis of the COR with urban, low-income preschool children yielded three factors: Cognitive Skills, Social Engagement, and Coordinated Movement (Fantuzzo, Hightower, Grim, \& Montes, 2002). Each of these three COR dimensions demonstrated high internal consistency for urban Head Start children. Convergent and divergent validity has been established with standardized assessments of peer play, receptive vocabulary, and psychological adjustment (Fantuzzo et al., 2003; Fantuzzo et al., 2002).

Early academic success. The Early Screening Inventory Revised - Kindergarten (ESI-K; Meisels, Marsden, Wiske, \& Henderson, 1997) was used in this study as an indicator of early academic success. The ESI-K is a brief, 25-item individually administered test for children ages 4 years, 5 months to 6 years. It assesses three primary developmental areas: visual-motor adaptive, language and cognition, and gross motor skills. It provides both a total raw score and a total readiness score. The total raw score is used with the child's age to determine the child's cutoff rating (i.e., Refer, Rescreen, or OK). These three categories are standardized for children ages 3.0 to 6.0 years of age. The total readiness score is a composite indicator of skills across each of the three developmental domains. It was normed on a sample of 5,034 children across 60 classrooms in 10 states, including Head Start, public schools, private child care and preschools. Interrater and test-retest reliability coefficients for the entire sample were high. Predictive validity was established using the McCarthy Scales of Children’s Abilities (MSCA; McCarthy, 1972). The ESI-K was chosen due to its high predictive validity. Specifically, there is strong support for the predictive accuracy of ESI-K’s three classifications: “refer”, “rescreen”, and “OK”. Cost-matrix analyses provided evidence that these classifications distinguished between 
children who were referred and those who were not referred for further educational assessment (Meisels, 1997).

Procedures

Approval for the research activities was obtained from the Director of the Head Start Program and the Head Start Policy Council. Two types of data collection activities were conducted: one early in the fall and the second late in the spring of the school year. Data collected in the fall consisted of the ASPI and the PLBS completed by teachers as part of a program-wide assessment initiative. In the spring, individual direct assessments of children (TEMA and ESI-K) were conducted. Teachers also completed the COR as part of the program's routine end-of-the-year assessment. All teachers in the larger Head Start program had at least a Bachelor's degree and a state teaching credential for early childhood. Prior to data collection, graduate student research team members met with teachers individually to explain the purpose of the study and to clarify issues of confidentiality, informed consent and data collection procedures. Researchers then obtained permission from parents for their children's involvement in the study.

A team of graduate students with training in child development conducted individual TEMA and ESI-K assessments and were blind to the specific research objectives. Graduate students received extensive training in the TEMA and ESI-K prior to their administration. Children were assessed individually outside of the Head Start classroom in a quiet place following a brief “warm-up” period.

\section{Data Analyses}

Three sets of data analytic procedures were conducted. The first examined the higher order dimensionality of classroom approaches to learning and emotional and behavioral 
adjustment. The second examined the contribution of these derived behavioral dimensions to early academic readiness competencies. The third examined whether early problems in these dimensions placed children at risk for poor outcomes.

Latent structure of emotional and behavioral adjustment and approaches to learning. To determine the presence of an underlying latent structure accounting for common variance of the constructs of preschool learning behaviors and classroom emotional and behavioral adjustment, the five ASPI and three PLBS dimensions were subjected to a series of exploratory latent structure analyses. This set of analyses employed the larger sample of 1,764 children for which ASPI and PLBS were collected early in the school year. Using squared multiple correlations as initial communality estimates, both oblique (promax) and orthogonal (varimax, equamax) rotational methods were used, rotating from 2 - 4 factors (Snook \& Gorsuch, 1989).

The most parsimonious factor solution was evaluated based upon multiple criteria that: (a) satisfied the constraints of tests for the number of factors [e.g., Cattell's scree test (Cattell, 1966), minimum-average partialing (Velicer, 1976), and parallel analysis (Buja \& Eyuboglu, 1992; Horn, 1965)]; (b) retained at least three items per factor with salient loadings, where loadings $\geq .50$ are considered salient; (c) yielded high internal consistency for each factor, with internal consistency (alpha coefficients) $\geq .70$; (d) yielded low interfactor correlations ( $\leq .30$ ); (e) held simple structure (mutually exclusive assignment of items to factors with the maximum number of items retained); and (f) comported with the empirical psychological literature.

Factor scores were calculated using precision-weighted scores based on the final factor solution (Nunnaly, 1978). Internal consistency values were calculated for factors according to Nunnaly’s (1978, p. 250) formula for the reliability of linear combinations. Specificity values were calculated to determine the reliable and unique variance associated with each factor by 
subtracting each factor's communality (proportion of common variance within each scale) from its alpha coefficient (Gorsuch, 1983). A two-way multivariate analysis of variance was conducted to determine if there were significant age and sex differences across derived higherorder behavioral dimensions.

Unique contribution to early mathematics ability and other classroom learning outcomes. The second set of analyses was conducted to determine the relationship between the derived behavioral dimensions assessed early in the year and the TEMA and COR assessed at the end of the year. First, bivariate correlations were attained between the derived behavioral dimensions and all three outcomes-- ESI-K, COR and TEMA. Then, a series of hierarchical setwise multiple regression models were employed to examine the unique contribution of the derived behavioral dimensions to these outcomes. Separate models were constructed for the TEMA and COR outcomes. Child demographic variables (age, gender) were applied as control variables to account for variation in the criterion dimension by entering them first as a separate set. Then, the behavioral dimensions were entered each as final independent sets to assess their unique contribution to the outcomes. For multivariate models (e.g., COR), the multivariate statistic, Wilks’ Lambda ( $\Lambda$ ) was applied to control for Type I error and examined before inspecting the significance of the model for each dependent variable and the incremental value of each set entered. The best model was evaluated in terms of: (a) the overall $R^{2}$ statistic, the proportion of variance in the criterion variable, explained by the best linear combination of the independent sets; and (b) the partial $r^{2}$ statistic, which is the amount of variance uniquely associated with the last set entered, in this case, the behavioral dimensions. The sample sizes of 145 and 189 children (for TEMA and COR respectively) provided adequate statistical power for these analyses, since a minimum sample of 107 is required to detect a medium effect with four 
explanatory variables (with power set at .80 and alpha set at a .05 significance level) (Cohen, 1992).

Prediction of risk according to an indicator of early academic success. The third set of analyses was conducted to determine if early problems in the derived behavioral dimensions placed children at risk according to an established indicator of early academic success (ESI-K). Logistic regression analysis was used to examine the association of unique behavioral dimensions to the outcome variable, controlling for age and gender. Multiple logistic regression was chosen because it is suitable for examination of a dichotomous outcome and yields oddsratios (Wright, 1995). Additionally, multiple logistic regression controlled for the effect of the demographic variables (gender and age) as covariates, by simultaneously entering them into the model. The overall chi-square statistic was examined to determine if the model was significant and therefore whether the individual Wald chi-squares could be examined. For each significant Wald chi-square, the odds-ratio was inspected to assess its relative contribution to the outcome variable. The odds-ratio is more easily interpreted as the degree of risk exerted by the independent variables on the dependent variable.

\section{Results}

\section{Latent Structure Analyses}

The two-factor, orthogonal (varimax) solution produced the most useful and parsimonious solution that satisfied the five central criteria for retention. This structure produced two psychologically meaningful factors: Regulated Behavior and Academically Disengaged Behavior. The first factor, Regulated Behavior, was comprised of high positive loadings for the Attention/Persistence and Attitude toward Learning PLBS scales, and negative loadings for Aggressive and Inattentive/Hyperactive ASPI scales. The second factor, Academically 
Disengaged Behavior, was comprised of positive loadings for Withdrawn/Low Energy and Socially Reticent ASPI scales and a negative loading for the PLBS Competence/Motivation scale. Table 2 displays the two factors with their respective loadings. Each factor demonstrated high internal consistency (Cronbach’s alpha .94 and .89 for Regulated Behavior and Academically Disengaged Behavior, respectively) and low inter-factor correlations (-.08). Both factors had specificity values that exceeded error variance. Table 3 displays the inter-factor correlations and variance components of the derived behavioral factors.

Age and Sex Differences

Significant age and sex differences across derived higher-order behavioral dimensions were investigated using a MANOVA with the latent structure sample $(N=1,764)$. A two-way multivariate analysis of variance was conducted where the first factor represented child age (older or younger children) and the second factor, child gender. Age was dichotomized at the sample median age split (60 months). There were significant age and gender differences on the Regulated Behavior dimension, $F(3,1760)=33.68, p<.0001$. Older children $(M=51.34, S D=$ 9.54) and girls $(M=51.89 S D=8.92)$ showed higher levels of Regulated Behavior than younger children $(M=48.74, S D=10.27)$ and boys $(M=48.08, S D=10.66)$. On the Academically Disengaged dimension, there were significant age differences only, $F(3,1760)=18.60, p<$ .0001 . Younger children $(M=51.62, S D=10.24)$ demonstrated higher levels of Academically Disengaged behavior than older children $(M=48.25, S D=9.44)$. There were no significant gender differences on this dimension with girls $(M=49.87, S D=9.97)$ and boys $(M=50.13, S D$ $=10.04$ ) demonstrating comparable levels of disengaged behavior.

Bivariate Relationship between Classroom Behavioral Dimensions and Head Start Outcomes

The bivariate correlations between classroom behavioral factors assessed in the fall and 
end-of-the-year measures of early mathematics ability (TEMA), classroom learning competency (COR), and an established indicator of academic success (ESI-K) are displayed in Table 4. A number of significant bivariate relationships emerged that provided convergent and divergent validity for the derived behavioral dimensions. Regulated behavior was positively associated with all outcomes while academically disengaged behavior was negatively associated with all readiness outcomes.

\section{Unique Contribution to Head Start Outcomes}

Contribution to early mathematics ability. Table 5 displays the results from the hierarchical setwise regression model indicating the amount of variation in early mathematics ability (TEMA) explained by the derived classroom behavioral factors [after accounting for variance attributable to the covariates (child age and gender)]. The overall model was significant, $F[4,144]=9.48, p<.0001$. Each behavioral factor accounted for a substantial amount of variance in early mathematics ability. Regulated Behavior accounted for $8.8 \%$ of the variance in early mathematics ability as indicated by the partial $r^{2}(F=15.00, p<.001)$. Academically Disengaged Behavior accounted for $4.4 \%$ of the variance in this outcome as indicated by the partial $r^{2}(F=7.88, p<.01)$. Standardized beta coefficients for each of the behavioral factors illustrate differential prediction patterns. Regulated behavior early in the year was associated with higher early mathematics ability at the end of the year $(\beta=.29, p<.001)$ and academically disengaged behavior was associated with lower early mathematics ability $(\beta=-.22, p<.01)$.

Contribution to classroom learning competence. Table 5 displays the results from the hierarchical setwise regression model indicating the amount of variation in classroom learning competence (COR) explained by the derived classroom behavioral factors [after accounting for variance attributable to the covariates (child age and gender)]. The overall multivariate statistic, 
Wilks’ Lambda was significant (Wilks’ $\Lambda=.65, F[12,481.82]=7.12, p<.0001$ ), permitting further inspection of the significance of each of the three dependent variable models (Cognitive Skills, Social Engagement, and Coordinated Movement).

All three models were significant, $F[4,188]=13.77, p<.0001$ for Cognitive Skills, $F$ $[4,188]=16.02, p<.0001$ for Social Engagement, and $F[4,188]=13.63, p<.0001$ for Coordinated Movement. Standardized beta coefficients for each of the behavioral factors illustrate differential prediction patterns. Regulated behavior at the beginning of the year was associated with higher learning outcomes $(\beta=.17, p<.05, \beta=.31, p<.0001, \beta=.21, p<.01)$ and academically disengaged behavior was associated with lower learning outcomes $(\beta=-.17, p$ $<.0001, \beta=-.31, p<.0001, \beta=-.34, p<.0001$ ) for cognitive skills, social engagement and coordinated movement respectively. Each behavioral factor also accounted for a substantial amount of variance in each of three dimensions of classroom learning. Regulated Behavior accounted for $2.6 \%$ of the variance in Cognitive Skills as indicated by the partial $r^{2}(F=6.21, p$ $<.05), 8.5 \%$ of the variance in Social Engagement as indicated by the partial $r^{2}(F=21.18, p<$ $.0001)$, and $4.0 \%$ of the variance in Coordinated Movement as indicated by the partial $r^{2}(F=$ 9.41, $p<.01$ ). Academically Disengaged Behavior accounted for a greater amount of variance in classroom learning outcomes accounting for $7.8 \%$ of the variance in Cognitive Skills as indicated by the partial $r^{2}(F=18.06, p<.0001), 10.8 \%$ of the variance in Social Engagement as indicated by the partial $r^{2}(F=24.23, p<.0001)$, and $12.4 \%$ of the variance in Coordinated Movement as indicated by the partial $r^{2}(F=28.22, p<.0001)$.

Prediction of Risk on an Indicator of Early Academic Success

The Regulated Behavior and Academically Disengaged Behavior dimensions were dichotomized at 1.5 standard deviations above or below the mean, depending on the valence of 
the dimension. Specifically, children scoring 1.5 standard deviations below the mean on the Regulated Behavior dimension were classified with poor regulated behavior. Children scoring 1.5 standard deviations above the mean on the Academically Disengaged Behavior dimension were classified with poor academically engaged behavior. Children's scores on the ESI-K were dichotomized according to published “risk” screening cut-offs for each age range (Meisels et al., 1997). Using these published conventions, $17 \%(n=40)$ of the children in the outcome sample were classified in the "at risk” category on the ESI-K. Children classified in this "risk" group according to Meisels et al. (1997), are those who are in need of a referral for a more comprehensive educational evaluation. According to Meisels et al. (1997), across a number of published studies approximately 6\% of children are identified as being at high-risk for school failure using this developmental screener. This finding indicates that children evidencing poor academically engaged behavior or poor regulated behavior are disproportionately more likely to be at risk for school failure.

The Score Statistic was significant (chi-square $=64.67, p<.0001$ ) for the multiple logistic regression model indicating that the individual explanatory variables could be examined. Controlling for age and gender, poor behavioral regulation and poor academic engagement had significant independent relationships with poor performance on early academic success (ESI-K). Both odds ratios for the behavioral dimensions were greater than one, indicating increased risk in relationship to the ESI-K. The odds ratio for poor regulated behavior was 13.41 (Wald chi-square $=19.3, p<.0001$ ); the odds ratio for poor academically engaged behavior was 9.77 (Wald chisquare $=20.9, p<.0001)$. Children with poor regulated behavior were 13 times more likely to be placed in the ESI-K “risk” group. Children with poor academic engagement were 10 times more likely to be at risk. Neither age nor gender was a significant explanatory variable in this model. 


\section{Discussion}

The present study was designed to address three primary research questions. First, are there distinct and reliable higher order relationships among classroom approaches to learning and emotional and behavioral adjustment constructs for low-income preschool children and are there age and gender differences? Second, are these behavioral dimensions uniquely associated with early mathematics ability and other classroom learning outcomes, controlling for age and gender differences? Third, do these dimensions differentially predict poor future academic performance controlling for age and gender differences? Two distinct and reliable, higher-order dimensions of classroom adjustment behavior were found—-Regulated and Academically Disengaged Behavior. These accounted for common variance in the constructs of classroom approaches to learning and emotional and behavioral adjustment assessed early in the Head Start year. Regulated Behavior reflected positive approaches to learning and low levels of classroom behavior problems.

Overall, high Regulated Behavior showed positive social interactions and attention control in the context of instruction. Students scoring high on Regulated Behavior were able to take instructional feedback well from teachers and peers, evidenced low levels of aggressive behavior and relatively high levels of attention and persistence to collaborative learning tasks with teachers and peers. Academically Disengaged Behavior, represented problematic classroom behavior related to difficulty making substantial connections to learning activities. This dimension included both low competence motivation and high levels of withdrawn, underactive behavior problems that impede active involvement in classroom learning opportunities.

Age differences were found on the higher order behavioral dimensions. Younger children consistently demonstrated higher problem behavior (Academically Disengaged) and lower levels of adaptive behavior (Regulated Behavior) than older children. These findings are consistent 
with developmental expectations for younger versus older children and comport with recent studies in Head Start suggesting that younger children demonstrate less emotional regulation and greater withdrawn and inattentive behavior problems in the classroom than older children (Coolahan et al., 2000; Fantuzzo et al., 2001; Lutz et al., 2002; Mendez et al., 2002). Gender findings revealed that girls demonstrated significantly higher Regulated Behavior than boys. This finding is consistent with research suggesting that preschool girls demonstrate greater selfcontrol and less externalizing classroom behavior problems than boys. Such studies indicate that boys demonstrate higher levels of classroom behavior problems, particularly externalizing and disruptive problems than girls (Coolahan et al., 2000; Fantuzzo et al., 2001; Lutz et al., 2002; Mendez et al., 2002).

Both of the derived higher-order dimensions contributed unique variance to the prediction of early mathematics ability and general classroom competencies in Head Start after controlling for the variance attributable to children's age and gender. Academically disengaged behavior (e.g., lower motivation and higher underactive adjustment problems) uniquely contributed to the prediction of general classroom outcomes and specific mathematics outcomes. Early classroom disengagement was associated with lower cognitive, social, and motor outcomes, as well as lower performance on mathematics skills at the end of Head Start. These findings underscore the important influence of preschool children’s active engagement in classroom learning experiences on their achievement in Head Start.

A series of research studies conducted in Head Start support the finding that preschool children with difficulties engaging socially and connecting to learning opportunities within the classroom environment, perform poorly in important areas of school readiness prior to kindergarten entry (Coolahan et al., 2000; Fantuzzo et al., 2003; Fantuzzo et al., 2004) as well as 
on first grade outcomes (Downer \& Pianta, 2006). For example, Fantuzzo et al. (2003) found that children demonstrating early withdrawn (socially reticent and low energy) problem behaviors performed the most poorly on academic and social outcomes at the end of the year. With regard to learning behaviors, Fantuzzo et al. (2004) also found that children with low competence motivation evidenced higher disconnected peer play at home and at school, as well as lower autonomous classroom behavior. Downer and Pianta (2006) found that children’s early social competence mediated the relationship between their early experiences and first grade academic achievement.

The higher-order dimension, Regulated Behavior, also contributed a unique amount of variance to general classroom learning and early mathematics outcomes. While contributing a relatively smaller amount of variance to motor outcomes, regulated behavior contributed a significantly higher amount of variance to children's social engagement and mathematics outcomes. These findings suggest a relationship between behavioral regulation assessed early in the year and both social engagement in learning and mathematics ability at the end of Head Start.

A body of research supports the overall influence of regulated behavior and self-control on social engagement within the preschool classroom (Denham, 1998; Denham, Blair, DeMulder, Levitas, Sawyer, Auerbach-Major, et al., 2003; Fabes et al., 1999; Raver, 2002, Raver \& Zigler, 2004). Research studies conducted specifically in Head Start demonstrate that children evidencing difficulties with behavioral self-control, reflected in socially disruptive behavior problems in the classroom display difficulties engaging successfully with peers (Coolahan et al., 2000; Fantuzzo et al., 2003; Fantuzzo et al., 2004; Fantuzzo, Sekino, \& Cohen, 2004; Lutz et al., 2002; Olson, 1992). Fantuzzo et al. (2003) suggest that early aggressive and inattentive behavior problems predict higher disruptive peer play in the Head Start classroom at 
the end of the year. Additionally Fantuzzo, Sekino, et al. (2004) found a strong relationship between task persistence, attention and positive attitude toward learning and self-regulated behavior within the context of social relationships within the classroom. Further, Coolahan et al. (2000) demonstrated that the same positive learning behaviors were related to positive classroom peer engagement and interaction. However, this present study is one of the first to examine the relationship between behavioral regulation and preschool mathematics ability for urban, Head Start children.

Finally, each of the higher order factors contributed independently to the prediction of academic risk controlling for child demographics. Of the overall sample, $17 \%$ of the children fell in the "at risk" category at the end of their Head Start experience. Children classified in this “risk” group according to Meisels et al. (1997), are those most in need of a referral for a more comprehensive educational evaluation prior to kindergarten entry. Early in the year, children demonstrating the highest levels of disengaged behavior, compared to other peers, were 13 times more likely to fall in the at-risk referral category on the ESI-K. Children evidencing significantly low levels of regulated behavior were 10 times more likely than their peer to be classified in the referral category. Both early difficulties in engagement and regulation uniquely predicted future difficulties. This suggests that both sets of skills are critical to early academic success for young children.

Future Research

The purpose of this study was to focus on the influence of early classroom behavioral dimensions as reported by teachers in Head Start on important kindergarten readiness outcomes. Clearly, teacher assessments of early classroom behavior were related significantly to key outcomes in Head Start. This indicates that Head Start teachers are making important distinctions 
in the assessment of preschool social, emotional, and behavioral adjustment. These present findings are qualified by the fact that teachers in this large urban Head Start program were teachers with bachelor degrees. An evaluation of teacher assessments in early childhood must be qualified by the level of training teachers have in early childhood education. Teachers with limited training and experience may not be able to make the distinction reflected in this study.

While the instrumentation to assess classroom behavioral constructs is limited for this population, there is a need for additional studies using alternative methods and sources for assessments of children's classroom social, emotional, and behavioral adjustment to confirm the present findings. Each of the multi-dimensional, teacher rating scales used in this study have been validated with Head Start children using direct assessments, however, source variance may have contributed to the teacher observations of classroom learning competency (COR) at the end of the Head Start year. The direct child assessments of early mathematics ability (TEMA) and early learning success (ESI-K) on the other hand represented different methods and different sources than the teacher assessments of classroom behaviors used early in the Head Start year. Furthermore, future research should examine the relationships between each of the two dimensions of Academically Disengaged Behavior and Regulated Behavior to a diverse set of early reading competencies and additional social adjustment measures associated with early school success. The TEMA reflected a range of early mathematic skills whereas the COR represents only a limited number of early reading and social indicators. A more comprehensive examination of the relationship of these dimensions to other facets of reading competency (e.g., vocabulary, phonemic awareness, and listening comprehension) and social adjustment could illuminate more distinctive contributions of each dimension. 
In addition, this study was a short-term longitudinal study conducted across two time points within the Head Start year. Investigating the unique impact of the two higher-order dimensions would be strengthened by following the children through their transition to kindergarten and from kindergarten to primary grades. A more extensive longitudinal study would allow investigation of the relationship of these dimensions to a more diverse set of early academic and social adjustment outcomes and how they may be influenced by elementary school characteristics.

Implications for Policy and Practice

There are a number of important implications of this research. This study extends our understanding of classroom behavioral adjustment by capturing children’s functioning across key dimensions within the context of natural, routine preschool situations by natural contributors to children’s learning-- teachers (Fantuzzo, McWayne, \& Bulotsky, 2003). With an increasing emphasis on early academic readiness for Head Start children, the important role of early social, emotional, and behavioral competencies can not be overlooked (Raver \& Zigler, 2004). Experts in the field call for research that extends our understanding of how these foundational skills foster learning within the preschool classroom (Raver \& Knitzer). The present study demonstrates that preschool teachers can use valid rating scales early in the year to identify two major dimensions of classroom behavioral constructs that are associated with readiness competencies and risk for poor academic performance. These findings support the existing Head Start policy requiring early identification of children evidencing social, emotional, and behavioral special needs (Lopez, Tarullo, Forness, \& Boyce, 2000; USDHHS, 2002). Early assessments of social emotional competencies, like the ones in this study, that account for a significant amount of variance in readiness outcomes and risk for poor early school performance 
prior to kindergarten entry are important to both the purposes of Head Start national standards (USDHHS, 2003) and the No Child Left Behind legislation (U.S. Department of Education, 2004).

Historically, for early childhood educators, the issue has not been "if” teachers should screen for social/emotional difficulties, but "how" to screen and the merits of screening. There has been clear documented resistance and underreporting of these difficulties by preschool teachers. Empirical studies question the validity of asking early childhood educators to use decontextualized checklists of behavioral problems to describe low-income, preschool children’s classroom behaviors (Fantuzzo et al., 2001; Lutz, 1999). Rather than use these checklists, early childhood educators have underreported the incidence of emotional and behavioral problems in the classroom to avoid stigmatizing children with labels that are not associated with needed classroom-based services (Fantuzzo et al., 1999; Lutz et al., 2002; Mallory \& Kearns, 1988; Piotrowski, Collins, Knitzer, \& Robinson, 1994).

The ASPI and PLBS teacher rating instruments used in this study were developed in collaboration with teachers for teachers' use. They are tied to classroom context and have been used with high levels of teacher participation. Research has shown that they detect valid and distinct dimensions of classroom functioning (see Measures section). This study shows that collectively they identify salient higher-order dimensions that account for unique variance in predicting later outcomes.

Early childhood educators could use these dimensions, derived from the ASPI and PLBS data, to contribute to an early identification and early intervention system. Such a system could include systematic screening procedures to prioritize children's needs based on the degree of their need. Subsequently, comprehensive investigations could be conducted: (a) to explore the 
specific circumstances in the classroom context for identified children, (b) to assess other domains of child functioning (e.g., language, cognition, and motor development), and (c) to evaluate the influences of other relevant contexts (i.e., home and neighborhood) on classroom behavioral functioning.

More intensive and systematic assessments could inform the development of contextually relevant intervention strategies. Clearly, for assessment to be used in a valid manner by early childhood educators it must be instrumental to informing curriculum that intentionally fosters critical social-emotional skills. Research, such as the present study, indicates the multidimensional nature of these skills and their close association to the achievement of early literacy and mathematic skills. This addresses the advocates' concerns that interventions to promote social-emotional development do not get lost in the contemporary push for early literacy skills (Raver \& Zigler, 2004), which reflect an ‘either/or,' zero-sum game approach. Instead, evidence-based social/emotional curricula should be intentionally integrated with early reading and mathematics curricula to improve school readiness and future school adjustment. 


\section{References}

Buja, A., \& Eyuboglu, N. (1992). Remarks on parallel analysis. Multivariate Behavioral Research, 27, 509-540.

Bulotsky-Shearer, R. \& Fantuzzo, J. (2004). Adjustment Scales for Preschool Intervention: Extending validity and relevance across multiple perspectives. Psychology in the School, 41), $725-736$.

Cattell, R. B. (1966). The scree test for the number of factors. Multivariate Behavioral Research, 1, 245-276.

Cohen, J. (1992). A power primer. Psychological Bulletin, 112, 155-159.

Coolahan, K., Fantuzzo, J., Mendez, J., \& McDermott, P. (2000). Preschool peer interactions and readiness to learn: Relationships between classroom peer play and learning behaviors and conduct. Journal of Educational Psychology, 92, 458-465.

Denham, S. A. (1998). Emotional development in young children. New York: Guilford Press.

Denham, S. A., Blair, K. A., DeMulder, E., Levitas, J., Sawyer, K., Auerbach-Major, S., et al. (2003). Preschool emotional competence: Pathway to social competence. Child Development, 74, 238-256.

Fabes, R. A., Eisenberg, N., Jones, S., Smith, M., Guthrie, I., Poulin, R., et al. (1999). Regulation, emotionality, and preschoolers' socially competent peer interactions. Child Development, 70, 432-442.

Fantuzzo, J. , Bulotsky, R., McDermott, P., Mosca, S., \& Lutz, M. N. (2003). A multivariate analysis of emotional and behavioral adjustment and preschool educational outcomes. School Psychology Review, 32, 185-203. 
Fantuzzo, J. , Grim, S., Mordell, M., McDermott, P., Miller, L., \& Coolahan, K. (2001). A multivariate analysis of the revised Conners' Teacher Rating Scale with low-income, urban preschool children. Journal of Abnormal Child Psychology, 29, 141-152.

Fantuzzo, J., Hightower, D., Grim, S., \& Montes, G. (2002). Generalization of the Child Observation Record: A validity study of diverse samples of low-income preschool children. Early Childhood Research Quarterly, 17, 106-125.

Fantuzzo, J., Manz, P., \& McDermott, P. (1998). Preschool version of the Social Skills Rating System: An empirical analysis of its use with low-income preschool children. Journal of School Psychology, 36, 199-214.

Fantuzzo, J. , McWayne, C., \& Bulotsky, R. (2003). Forging strategic partnerships to advance mental health science and practice for vulnerable children. School Psychology Review, $32,17-37$.

Fantuzzo, J., Perry, M. A., \& McDermott, P. (2004). Preschool approaches to learning and their relationship to other relevant classroom competencies for low-income children. School Psychology Quarterly, 19, 212-230.

Fantuzzo, J., Sekino, Y., \& Cohen, H. L., (2004). An examination of the contributions of interactive peer play to salient classroom competencies for urban Head Start children. Psychology in the Schools, 41, 633-645.

Ginsberg, H. P. \& Baroodt, A. J. (1990). Test of Early Mathematics Ability. Texas: Pro-Ed.

Gorsuch, R. L. (1983). Factor Analysis (2nd ed.). Hillsdale, NJ: Lawrence Erlbaum Associates.

Green, L. F. \& Francis, J. M. (1988). Children’s learning skills at the infant and junior stages: A follow-on study. British Journal of Educational Psychology, 58, 120-126. 
Hammill, D., Ammer, J. J., Cronin, M. E., Mandlebaum, L. H., \& Quinby, S. S. (1987). QuickScore Achievement Test. Texas: Pro-Ed.

High/Scope Education Research Foundation. (1992). High/Scope Child Observation Record (COR) for ages 2 1⁄2 -6. Ypsilanti, MI: High/Scope Press.

Horn, J. L. (1965). A rationale and test for the number of factors in factor analysis. Psychometrika, 30, 179-185.

Huffman, L. C., Mehlinger, S. L., \& Kerivan, A. S. (2000). Risk factors for academic and behavioral problems at the beginning of school. In Off to a good start: Research on the risk factors for early school problems and selected federal policies affecting children's social and emotional development and their readiness for school. Chapel Hill: University of North Carolina, Frank Porter Graham Child Development Center.

Jordan, N.C., Kaplan, D., Olah, L.N., \& Locuniak, M.N. (2006). Number sense growth in kindergarten: A longitudinal investigation of children at risk for mathematics difficulties. Child Development, 77, 153-175.

Jordan, N.C., Huttonlocher, J., \& Levine, S.C. (1992). Assessing early arithmetic difficulties: Effects of verbal and nonverbal response types on calculation performance of middleand low-income children. Learning and Individual Differences, 6, 413-432.

Kagan, S. L., Moore, E., \& Bredekamp, S. (1995). Reconsidering children's early development and learning: Toward common views and vocabulary. Washington, DC: National Education Goals Panel.

Knitzer, J. (2003, January). Social and emotional development in young low-income children: What research tells us and why it matters for early school success. Paper presented at the 
Testimony presented at the Head Start Hearing, Russell Senate Office Building, Washington, DC.

Kolker, J. Osborne, D. \& Schnurer, E. (2004). Early child care and education: The need for a national policy. Washington, DC: Center for National Policy.

LaParo, K. M. \& Pianta, R. C. (2000). Predicting children's competence in the early years: A meta-analytic review. Review of Educational Research, 70, 443-484.

Lidz, C. S., (2003). Early childhood assessment. Hoboken, NJ: Wiley \& Sons.

Lonigan, C. J., Bloomfield, B. G., Anthony, J. L., Bacon, K. D., Phillips, B. M., \& Samwel, C. S. (1999). Relations among emergent literacy skills, behavior problems, and social competence in preschool children from low- and middle-income backgrounds. Topics in Early Childhood Special Education, 19, 40-53.

Lopez, M. L., Tarullo, L. B., Forness, S. R., \& Boyce, C. A. (2000). Early identification and intervention: Head Start's response to mental health challenges. Early Education \& Development, 11, 265-282.

Lutz, M. N., Fantuzzo, J., \& McDermott, P. (2002). Multidimensional assessment of emotional and behavioral adjustment problems of low-income preschool children: Development and initial validation. Early Childhood Research Quarterly, 17, 338-355.

Lynch, R. G. (2004). Exceptional returns: Economic, fiscal, and social benefits of investment in early childhood development. Washington, DC: Economic Policy Institute.

Mallory, B. L., \& Kearns, G. M. (1998). Consequences of categorical labeling of preschool children. Topics in Early Childhood Special Education, 8, 39-50.

McCarthy, D. A. (1972). McCarthy Scales of Children's Abilities. New York: Psychological Corporation. 
McClelland, M. M., Morrison, F. J. \& Holmes, D. L. (2000). Children at risk for early academic problems: The role of learning related social skills. Early childhood research quarterly, 15, 307-329.

McDermott, P. A. (1984). Comparative functions of preschool learning style and IQ in predicting future academic performance. Contemporary Educational Psychology, 9, 38-47.

McDermott, P. A. (1999). National scales of differential learning behaviors among American children and adolescents. School Psychology Review, 28, 280-291.

McDermott, P. A., Green, L. F., Francis, J. M., \& Stott, D. H. (2000). Learning Behaviors Scale. Philadelphia, PA: Edumetric and Clinical Science.

McDermott, P. A., Leigh, N. M., \& Perry, M. A. (2002). Development and validation of the Preschool Learning Behaviors Scale. Psychology in the Schools, 39, 353-365.

McDermott, P.A., Mordell, M, \& Stoltzfus, J.C. (2001). The organization of student performance in American schools: Discipline, motivation, verbal learning, and nonverbal learning. Journal of Educational Psychology, 93, 65-76.

McWayne, C. M., Fantuzzo, J. W., \& McDermott, P. A. (2004). Preschool competency in context: An investigation of the unique contribution of child competencies to early academic success. Developmental Psychology, 40, 633-645.

Meisels, S. J., Marsden, D. B., Wiske, M. S., \& Henderson, L. W. (1997). The Early Screening Inventory (rev. ed.). Ann Arbor, MI: Rebus.

Mendez, J. L., McDermott, P., \& Fantuzzo, J. (2002). Identifying and promoting social competence with African American preschool children: Developmental and contextual considerations. Psychology in the Schools, 39, 111-123. 
National Education Goals Panel (NEGP). (1997). Getting a good start in school. Washington, DC: National Education Goals Panel.

National Research Council. (1998). Preventing reading difficulties in young children. Washington, DC: National Academy Press.

National Research Council. (2000). From neurons to neighborhoods: The science of early childhood development. Washington, DC: National Academy Press.

National Research Council. (2001). Eager to learn: Educating our preschoolers. Washington, DC: National Academy Press.

Newcomer, P. (2001). Diagnostic Achievement Battery ( $3^{\text {rd }}$ ed). Texas: Pro-Ed.

Nunnaly, J. (1978). Psychometric theory. New York: McGraw-Hill.

Olson, S. L. (1992). Development of conduct problems and peer rejection in preschool children: A social systems analysis. Journal of Abnormal Child Psychology, 20, 327-350.

Piotrkowski, C. S., Collins, R. C., Knitzer, J., \& Robinson, R. (1994). Strengthening mental health services in Head Start: A challenge for the 1990s. American Psychologist, 49, 133139.

Raver, C. C. (2002). Emotions matter: Making the case for the role of young children's emotional development for early school readiness. Retrieved November 1, 2003, from http://www.srcd.org/spr.html.

Raver, C. C., \& Knitzer, J. (2002). Ready to Enter: What research tells policymakers about strategies to promote social and emotional school readiness among three-and four-yearold children. New York: National Center for Children in Poverty, Mailman School of Public Health, Columbia University. 
Raver, C. \& Zigler, E., (2004). Another step back? Assessing readiness in Head Start. Beyond the Journal: Young Children on the Web, 1-5. From http://www.journal.naeyc.org/btj/200401/Raver.pdf.

Reyna, V. F. (2005). The No Child Left Behind Act, scientific research and federal education policy: A view from Washington, DC. In G.D. Phye, D.H. Robinson, \& J.R. Levin (Eds.), Empirical methods for evaluating educational interventions (pp. 29-52). New York: Elsevier Academic Press.

Rimm-Kaufman, S. E., Pianta, R. C, \& Cox, M. J. (2000). Teachers' judgments of problems in the transition to kindergarten. Early Childhood Research Quarterly, 15, 147-166.

Sameroff, A. J. \& Fiese, B. H. (2000). Models of development and developmental risk. In C. H. Zeanah, Jr. (ed.). Handbook of infant mental health. New York: The Guilford Press.

Schweinhart, L. J., Barnes, H. V., \& Weikart, D. P. (1993). Significant benefits: The High/Scope Perry Preschool Study through age 27. Ypsilanti, MI: High/Scope Press.

Snook, S. C., \& Gorsuch, R. L. (1989). Component analysis versus common factor analysis: A Monte Carlo study. Psychological Bulletin, 106, 148-154.

Stott, D. H., McDermott, P. A., Green, L. F., \& Francis, J. M. (1988). Study of children's learning behaviors. San Antonio: The Psychological Corporation.

Teo, A., Carlson, E., Mathieu, P. J., Egeland, B., \& Sroufe, L. A. (1996). A prospective longitudinal study of psychosocial predictors of achievement. Journal of School Psychology, 34, 285-306.

U.S. Department of Education. (2004). Four Pillars of NCLB. Retrieved March 19, 2004, from http://www.ed.gov/nclb/overview/intro/4pillars.html 
U.S. Department of Health and Human Services. (2002). Program performance standards for the operation of Head Start programs by grantee and delegate agencies, 45 C.F.R. Part 1304, Federal Register, 61, 57186-57227. Washington, DC: U.S. Government Printing Office.

U.S. Department of Health and Human Services (USDHHS). (2001). Report of the Surgeon General's Conference on Children's Mental Health: A National Action Agenda. Washington, DC: U.S. Department of Health and Human Services.

U.S. Department of Health and Human Services (USDHHS). (2003). The Head Start child's outcome framework. Retrieved May 5, 2005, from http://www.headstartinfo.org/publications/hsbulletin76/hsb76_09.htm\#top

U.S. Department of Health and Human Services (USDHHS). (2005). Head Start program fact sheet. Retrieved September 27, 2006, from http://www2.acf.dhhs.gov/programs/hsb/research/2005.htm

Washington, DC: U.S. Department of Health and Human Services.

Velicer, W. F. (1976). Determining the number of components from the matrix of partial correlations. Psychometrika, 41, 321-327.

Velting, O. N. \& Whitehurst, G. J. (1997). Inattention-hyperactivity and reading achievement in children from low-income families: A longitudinal model. Journal of Abnormal Child Psychology, 25, 321-331.

Wright, R. (1995). Logistic regression. In L. Grimm \& P. Yarold (eds.), Reading and understanding multivariate statistics. Washington, DC: American Psychological Association.

Zigler, E., Finn-Stevenson, M. \& Hall, N. W. (2002). The first three years and beyond. CT: Yale University Press. 
Table 1

Constructs Assessed and Instruments Used

$\begin{array}{lll}\text { Construct } & \text { Instrument }\end{array}$

Early social-emotional classroom behavior

Emotional and behavioral adjustment

Adjustment Scales for Preschool Intervention (ASPI)

Aggressive, oppositional, inattentive/hyperactive

withdrawn/low energy, socially reticent behavior

Approaches to learning

Preschool Learning Behaviors Scale (PLBS)

Competence motivation

Attention/persistence

Attitudes toward learning

Readiness outcomes

Classroom learning competence

Child Observation Record (COR)

Cognitive skills

Social engagement

Coordinated movement

Early mathematics ability

Early learning success

Test of Early Mathematics Ability (TEMA-2)

Early Screening Inventory Revised-Kindergarten (ESI-K) 
Table 2

Varimax Rotated Common Factor Structure for Preschool Emotional and Behavioral Adjustment and Learning Behaviors

\begin{tabular}{|c|c|c|}
\hline Behavioral dimension & $\begin{array}{l}\text { Regulated }^{\mathrm{a}} \\
\text { Behavior }\end{array}$ & $\begin{array}{c}\text { Academically Disengaged } \\
\text { Behavior }\end{array}$ \\
\hline
\end{tabular}

PLBS Competence Motivation

$-.60$

PLBS Attention/Persistence .78

PLBS Attitude toward Learning

ASPI Aggressive

$-.70$

ASPI Inattentive/Hyperactive

$-.75$

ASPI Oppositional

ASPI Withdrawn/Low Energy

.56

ASPI Socially Reticent

.57

$N=1764$.

${ }^{\text {a }}$ Entries are factor loadings derived from varimax orthogonal rotation. Only salient loadings are displayed, where loadings $>.50$ are considered salient. PLBS= Preschool Learning Behavior Scales. ASPI= Adjustment Scales for Preschool Intervention. 
Table 3

Intercorrelations and Variance Components for Behavioral Dimensions

\begin{tabular}{|c|c|c|c|c|c|c|}
\hline \multirow[b]{2}{*}{ Behavioral Dimension } & \multicolumn{2}{|c|}{ Correlation $^{\mathrm{a}}$} & \multirow[t]{2}{*}{ Coefficient alpha ${ }^{\mathrm{b}}$} & \multicolumn{3}{|c|}{ Proportion of variance ${ }^{c}$} \\
\hline & Disc Behavior & Unmot Behavior & & Common & Specific & Error \\
\hline Regulated Behavior & ----- & $-.08 * *$ & .94 & .04 & .90 & .06 \\
\hline Acad. Disengaged Behavior & $-.08^{* *}$ & ----- & .89 & .04 & .85 & .11 \\
\hline Average & & & & .04 & .88 & .09 \\
\hline
\end{tabular}

Note. $N=1764$.

${ }^{a}$ Intercorrelations are based on precision-weighted scores as derived through orthogonal common factoring. ${ }^{* *} p<.01$.

bInternal consistency is based on the weighted linear combination of the 8 behavioral dimensions (per Nunnally's 1978, p. 250

formula), where weights are determined in common factoring.

${ }^{\mathrm{c}}$ The total proportion of common variance is expressed by final communality estimates derived in second-order common factoring. Specific variance indicates the proportion of variance which is both reliable and unique to a particular dimension and is calculated by subtracting communality for a dimension from its alpha coefficient. Specific variance values that exceed error variance (where error variance $=1$ - coefficient alpha) are considered significant and are italicized. The sums of row entries for variance components $=1.0$. 
Table 4

Bivariate Correlations between Fall Behavioral Dimensions and Spring Outcomes

\begin{tabular}{|c|c|c|c|c|c|}
\hline & ESI-K & TEMA & $\begin{array}{l}\text { Cognitive } \\
\text { Skills }\end{array}$ & $\begin{array}{c}\text { Social } \\
\text { Engagement }\end{array}$ & $\begin{array}{c}\text { Coordinated } \\
\text { Movement }\end{array}$ \\
\hline \multicolumn{6}{|l|}{ ASPI dimensions } \\
\hline Aggressive & $-.16^{*}$ & $-.17^{*}$ & -.06 & $-.19 * *$ & -.10 \\
\hline Inattentive/Hyperactive & $-.26 * * * *$ & $-.28 * * *$ & $-.22 * *$ & $-.29 * * * *$ & $-.18 * *$ \\
\hline Oppositional & $-.16^{*}$ & -.05 & -.08 & $-.16^{*}$ & $-.15^{*}$ \\
\hline Withdrawn/Low Energy & $-.28 * * * *$ & -.15 & $-.26 * * *$ & $-.32 * * * *$ & $-.30 * * * *$ \\
\hline Socially Reticent & $-.20 * *$ & -.11 & $-.26 * * *$ & $-.26 * * *$ & $-.24 * * *$ \\
\hline \multicolumn{6}{|l|}{ PLBS dimensions } \\
\hline Competence Motivation & $.42 * * * *$ & $.39 * * * *$ & $.32 * * * *$ & $.39 * * * *$ & $.39 * * * *$ \\
\hline Attention/Persistence & $.51 * * * *$ & $.42 * * * *$ & $.33 * * * *$ & $.40 * * * *$ & $.36^{* * * *}$ \\
\hline Attitude Toward Learning & $.39 * * * *$ & $.27 * * *$ & $.24 * * *$ & $.34 * * * *$ & $.26 * * * *$ \\
\hline \multicolumn{6}{|l|}{ Behavioral dimensions } \\
\hline Regulated Behavior & $.41 * * * *$ & $.33 * * * *$ & $.25 * * *$ & $.36 * * * *$ & $.28 * * * *$ \\
\hline Academically Disengaged Behavior & $-.36 * * * *$ & $-.23 * *$ & $-.31 * * * *$ & $-.33 * * * *$ & $-.35 * * * *$ \\
\hline
\end{tabular}

$N=232, N=145, N=194, N=202, N=208$ for ESI-K, TEMA, Cognitive Skills, Social Engagement, and Coordinated Movement respectively. ${ }^{*} p<.05,{ }^{* *} p<.01,{ }^{*} * * p<.001, * * * * p<.0001$. 
Dimensions of Social-Emotional Classroom Behavior 4

Table 5

Prediction of End of the Year Academic Competencies by Fall Behavioral Dimensions

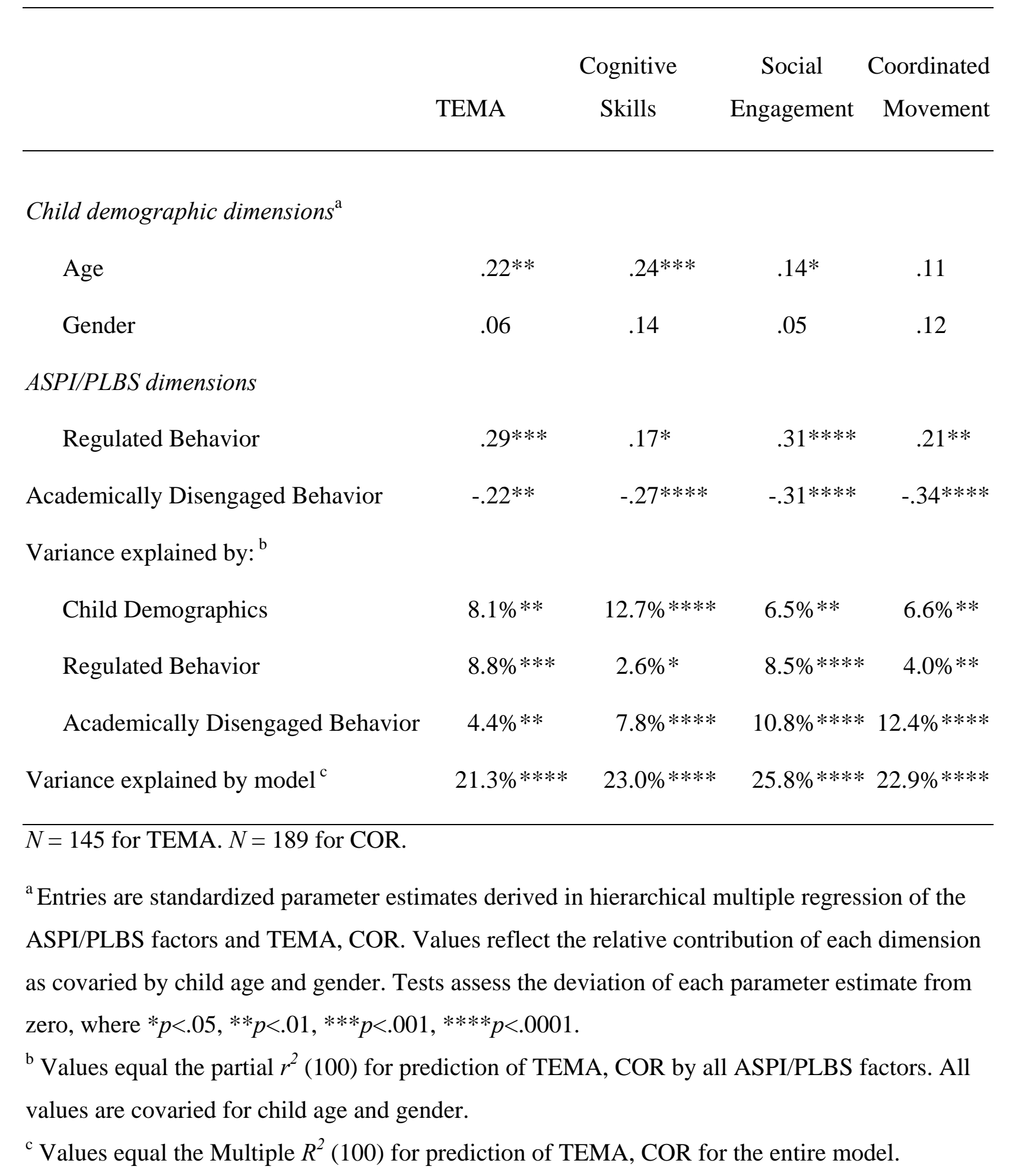


Table 6

Odds Ratios and Probability Levels for Demographic and Preschool Behavioral Factors on School Readiness (for highest risk children) (ESI-K)

Risk factor

ESI-K

Child demographic variables

Age (younger children) ${ }^{\mathrm{a}}$

Gender (boys)

.44

ASPI/PLBS factors

Low Regulated Behavior ${ }^{\mathrm{b}}$

$13.41^{* * * *}$

High Academically Disengaged Behavior ${ }^{c}$

$9.77 * * * *$

$N=232 .{ }^{*} p<.05,{ }^{* *} p<.01,{ }^{* * *} p<.001,{ }^{* * * *} p<.0001$.

${ }^{a}$ Based on median age split (less then 63.5 months).

${ }^{\mathrm{b}}$ Risk scores created based on $1.5 S D$ below the mean.

${ }^{\mathrm{c}}$ Risk scores created based on $1.5 S D$ above the mean. 